\title{
Ant Colony Optimized Fuzzy Control Solution for Frequency Oscillation Suppression
}

\author{
Y.K. Bhateshvar ${ }^{1}$, H.D. Mathur ${ }^{1}$, H. Siguerdidjane ${ }^{2}$ and R.C. Bansal ${ }^{3}$ \\ ${ }^{1}$ Department of Electrical and Electronics Engineering, BITS, Pilani, India \\ yogeshbhateshvar@gmail.com \\ ${ }^{2}$ Automatic Control Department, CentraleSupélec, Gif-sur-Yvette, France \\ ${ }^{3}$ Professor, Department of Electrical, Electronic and Computer Engineering, University of Pretoria, \\ South Africa
}

\begin{abstract}
This paper presents a novel approach in addressing a critical power system issue i.e. Automatic Generation Control (AGC) in smart grid scenario. It proposes the design and implementation of an optimized fuzzy logic controller (FLC) for AGC of interconnected power network. There are three different sources of power generation considered in two area interconnected model of power system. First area is equipped with single reheat thermal unit and a superconducting magnetic energy storage (SMES) unit while another has hydro unit with SMES. A multi stage ant colony optimization for optimal solution of fuzzy logic controller for tie-line and frequency oscillation suppression is proposed. The optimization of FLC is carried out four different stages. The first stage is optimization of range of input and output variables; second of membership function; third and fourth steps for rule base and rule’s weight optimization respectively. Another control approach also used and compared with multi-stage ACO is Genetic algorithm (GA) optimized PID controller to stabilize $P_{\text {tie-line }}$ and $\Delta f$ oscillations. A comprehensive analysis of traditional techniques and proposed techniques are presented on the basis of major dynamic performance parameters i.e. settling time and peak overshoot.
\end{abstract}

Keywords: Two-Area Power System, Automatic Generation Control, Fuzzy Logic Controller, Ant Colony Optimization, Genetic Algorithm, Superconducting Magnetic Energy Storage.

\section{INTRODUCTION}

The increasing concern of maintaining continuous balance between generation and load is pushing power engineers to evolve advance control strategies for effectively minimizing deviations in frequency and tie-line power. Automatic generation control is a system for a controlling power generation and frequency as per fluctuating load demand as well as to ensure the quality of power supply. Usually AGC has three stages of control: First, the primary control is offered by governors 
of the generators, which provide immediate action to sudden change of load. Second is secondary control which keeps frequency at its nominal value by adjusting the output of selected generators where a controller is needed. Last, tertiary control is an economic dispatch that is used to operate the system as economically as possible.

Various techniques have been explored in designing and implementing secondary control as it being critical. With the advent of smart grid technologies in the modern power system era, energy storage solutions may provide quick active power support to strengthen smooth operation when system is subjected to load perturbations. On the similar lines, quality power by means of new energy storage systems such as SMES [1], [2], ultra capacitor [3] etc are being considered for immediate power support. SMES, in particular, is seen as a viable option whenever demand arises. Despite having energy storage solution, oscillation suppression remains a challenge for power system operators. Therefore, researchers have also emphasized more on different control techniques for secondary control part in AGC. Intelligent controllers using neural network [4]-[7], fuzzy logic [8]-[10]. Optimization of PID controller with GA, PSO and differential evolution are also independently tried and presented in research studies [11]-[17]. It has been observed that literature lacks in suggesting a composite controller i.e. efficient optimized intelligent controller for two-area reheat thermal and hydro system integrated with SMES.

Fuzzy logic based controllers have widely accepted for different engineering and industrial applications as it is an appropriate choice for linear, non-linear system, complex or ill defined system. In this paper, integration of SMES with conventional power system and later, designing intelligent optimized controller to dampen oscillations are mainly focussed. Proposed study aims to model fuzzy logic based controller where various controller design stages are optimized using ant colony optimization. In ACO optimized fuzzy logic controller scaling factor, membership functions are optimized initially and later rule base and rule weight. Dynamic performance parameters mainly settling time and peak overshoot are considered in results for a detailed comparison in three approaches; (a) Ziegler -Nichols tuned PID (b) GA optimized PID and (c) ACO optimized fuzzy (ACOFC). Results of controlled power system model with and without SMES are also presented to show SMES impact. MATLAB/Simulink is used for all simulation purpose.

In this paper, section 2 describes about system examined, section 3 describes control strategy for frequency control, section 4 describes fuzzy logic controller optimized by ACO and section 5 describes results and discussion.

\section{SYSTEM EXAMINED}




\section{Automatic Generation Control for Two-Area Power System}

As mentioned in the previous section, power system owing to the growing size and complexity, sudden load fluctuation causes variation in the frequency and voltage of the system in the power plants and consequently difficult to analyze. The multi-area power system consists of interconnection of several power systems. Different algorithms are used and proposed ACOFLC is introduced in two area system by considering suitable objective function. Investigation has been carried out on a two area hydro-thermal power system connected by interconnected tie line and having reheat thermal unit in control area-1 and hydro generating unit in control area 2. Each area of the power system consists of speed governing system, turbine, and generator as shown in Fig. 1. The components shown in diagram are represented by their respective transfer function given in Appendix apart from this their parameter values also given in Appendix.

In AGC, the difference between actual generation and scheduled generation is termed as area control error (ACE) for interconnected power system [18].

$$
A C E_{i}=\sum_{j} \Delta P_{t i e, i j}+\beta_{i} \Delta f_{i}
$$

Where, $b_{i}$ is frequency bias constant, $\Delta f_{i}$ is frequency deviation, $\Delta P_{t i e, i j}$ is change in tie-line power and subscripts $i \& j$ indicate area 1 or 2 . Therefore, scheduled tie-line power flow between area-1 and area-2 is:

$$
\Delta P_{\text {tie12,sch }}=\Delta P_{L, A 1 \rightarrow A 2}-\Delta P_{L, A 2 \rightarrow A 1}
$$

\section{Superconducting Magnetic Energy Storage}

SMES is an energy storage system that can charge and discharge very fast with high quantity of power for short span of time. In recent year SMES is an emerging solution for power system application due to its fast charging and discharging capability. Basically, SMES system includes four parts, i.e. superconducting coil, power conditioning system, refrigeration system and control unit. The power conditioning system incorporates the inverter/rectifier circuit for conversion of AC to DC and vice versa. The charging and discharging of SMES occurs through power conditioning 
system. Refrigeration system maintains superconducting coil to critical temperature. Control unit is only responsible for mode of operation. Operating mode selection is done by controller based on inter-area oscillations. ACE is fed as an input signal to SMES control unit. SMES operate in three modes of operation; which are charging, discharging and charge sustain mode. During charging mode superconducting coil is charged from utility grid to a set value. In discharging mode, the stored energy is released to power system. Whenever there is a sudden release in a load then SMES comes to a charging mode and it immediately gets charged towards full value. As soon as system returns to steady state SMES returns to charge sustain mode [19], [20].

\subsubsection{SMES Modeling}

The block diagram of SMES unit is shown in Fig. 2. SMES is available for use for AGC once rated current is reached in the SMES coil. The $A C E_{i}$ is controller input of SMES unit and $U_{\text {smi }}$ is controller output. Controller output applied to converter and converter output is later applied to SMES coil, as described in (3) which gives change in voltage. This change is related to current by relation given in (4).

$$
\begin{aligned}
& \Delta V_{s m}(s)=\frac{1}{1+s T_{d c}} U_{s m i}(s)-\frac{K_{s m}}{1+s T_{d c}} \Delta I_{s m}(s) \\
& \Delta I_{s m}(s)=\frac{1}{s L} \Delta V_{s m}(s)
\end{aligned}
$$

The short term active power $\left(\Delta P_{s m}\right)$ corresponding to change in $A C E$ is represented by (5). This short term active power is used for frequency stabilization when interconnected area is subjected to change in load.

$$
\Delta P_{s m}=\left(I_{s m 0}+\Delta I_{s m}\right) \Delta V_{s m}
$$

Where,

$\Delta V_{s m}=$ incremental change in SMES voltage, $\Delta I_{s m}=$ incremental change in SMES dc current, $T_{d c}=$ convertor's time constant, $K_{s m}=$ feedback gain, L=inductance of SMES coil and $I_{s m 0}=$ initial dc current flow through SMES coil. 


\section{CONTROL STRATEGY FOR FREQUENCY CONTROL}

In this paper, PID controller is selected as controller for AGC. PID controller for AGC, in which $A C E_{i}$ selected as controller input and $K_{p}, K_{i}$ and $K_{d}$ are gains of controller and $U_{p i d}$ is output of controller.

$$
U_{p i d}=K_{p}\left(A C E_{i}\right)+K_{i}\left(\int A C E_{i} d t\right)+K_{d}\left(\frac{d A C E_{i}}{d t}\right)
$$

PID controller's gain values for AGC are obtained from Ziegler -Nichols tuning method and genetic algorithm based stochastic optimization method respectively.

\section{Ziegler-Nichols Tuning}

Ziegler-Nichols (ZN) tuning method is a heuristic type approach for PID Controller. This method is based on the selection of proportional gain to get sustained oscillations in closed loop, from which ultimate gain $K_{u}$ and oscillation period $T_{u}$ are obtained [21]. In this method, proportional controller is taken as a controller and proportional gain value $\left(K_{p}\right)$ is selected for which sustained oscillations occur. This value of proportional gain is called ultimate gain $K_{u}$ and time period $T_{u}$ of output response is called oscillation period. PI or PID controller gains can be tuned with formulas based on $K_{u}$ and $T_{u}$. Here PID controller gains are calculated from formulas as shown in Table 1.

\section{Genetic Algorithm}

GA is a stochastic search/optimization algorithm based on natural genetics mechanics, capable of finding optimal solution. This optimization is an iterative procedure, in which every iteration constant population size is maintained [22]. GA utilizes the different genetic operators for the improvement of the fitness of individual population solution. These genetic operators are selection, crossover, mutation and elite, respectively. By utilizing these different genetic operators, GA improves the fitness of individual population solution. Initially fixed number of random solutions are generated, and then in next iterations by genetic operators new population of same 
numbers of solution of improved fitness are generated. At selection process, each solution of population is evaluated by its fitness value, which is provided by the user defined objective function. In crossover process the pairs of selected solution will be selected by a defined method to generate new solutions. In mutation process the selected solution is randomly altered with a small probability which helps to prevent the GA being trapped in a local optimal solution [23]. The flow chart of GA used for PID controller optimization is shown in Fig. 3.

The objective function for PID optimization is based on the minimization of integral of absolute error (IAE). IAE is an error function, minimization of this function ensures less deviation, smooth and fast response. This objective function selected for GA is:

$$
J_{I A E}=\int_{0}^{T}\left(\left|A C E_{\text {area-1 }}\right|+\left|A C E_{\text {area-2 }}\right|\right) d t
$$

Here, $T$ is selected 30s for present system. The PID controller gains are obtained from GA optimization as shown in Table 2.

\section{FUZZY LOGIC CONTROLLER OPTIMIZED BY ACO}

\section{Design of FLC}

The FLC modelling consists of three steps, i.e. fuzzification, formation of fuzzy control rule base and defuzzification. In the process of fuzzification, input and output variables crisp values are converted into linguistic values. The control actions of a FLC are described by sets of linguistic rules. A dual input and single output type FLC is designed for SMES control. These two inputs are $A C E_{i}$ and $d A C E_{i} / d t$ and one output is $U_{i}$ for each control area, as shown in Fig. 4. Mamdani type fuzzy logic design is used for proposed controller [24], [25]. There are 3 triangular and 2 trapezoidal type membership functions considered for both inputs, as shown in Fig. 5. In the rule base, 25 rules are designed to get the desired response. There are two scaling factors $\left(K_{e} \& K_{c e}\right)$ for both input variables $\left(A C E_{i}, d A C E_{i}\right)$ respectively and two gain factors $K_{p u} \& K_{i u}$ as proportional and integral gains respectively. 


\section{Ant Colony Optimization}

ACO is one of popular meta-heuristic optimization. It is inspired from foraging behaviour of ants, they are able to find the shortest route between their nest and a food source. Ants can choose a path probabilistically based on pheromone deposition. They complete tour by selecting nodes according to state transition rule. Ants prefer those paths which are short and having high quantities of pheromone [26].

The Stigmergic behavior of ants allows them to communicate indirectly by depositing pheromone. Pheromone is an odorous chemical substance that real ants deposit and smell while walking. After an ant has found a solution, it dies. Finest solution found by global cooperation among ants in a colony.

ACO is efficiently able to search a finest solution. Self organizing behavior of ants converges to one path. As ants move from one node to another node, they deposit amount of pheromone deposit is proportional to quality of solution as per local pheromone updating rule. Once tour finished, amount of pheromone is updated again as per global updating rule, in this a quantity of pheromone deposited on those nodes that provides best so far solution up to current iteration.

Ants completed global pheromone updating rule, a fraction of pheromone evaporates and then each ants deposits a quantity of pheromone in proportional to fitness value. This complete process is iterated up to convergence. Local pheromone updating rule avoids early stagnation [27].

The Selection of nodes is based on random proportional rule as per Eq. (8).

$$
\begin{array}{r}
\rho: \quad \text { Evaporation rate }(0<\rho<1) \\
\qquad \tau_{i j}(t+1)=\tau_{i j}(t)+\sum_{a=1}^{N A} \Delta \tau_{i j}^{a}
\end{array}
$$

$$
\tau_{i j}(t+1)=(1-\rho) \tau_{i j}(t)
$$

$\Delta \tau_{i j}^{a}$ : Amount of pheromone left by each $a^{\text {th }}$ ant at $i j$ edge

NA: $\quad$ Total numbers of ant

$$
\Delta \tau_{i j}^{a}=\left\{\begin{array}{cc}
\frac{L^{\min }}{L^{a}} ; & \\
0 ; & \text { otherwise }
\end{array}\right\}
$$

$L^{\text {min }}$ : Best Fitness value found up last iteration

$L^{a}$ : Fitness value found by $a^{\text {th }}$ ant 
Probability eq.(12) determines that ant will situate on which adjacent node at time $(t)$. Where factor $\alpha$ and $\beta$ determines relative influence of phermone value and heuristic value on selection of next node. $\eta_{i j}$ is the inverse of the difference of objective function that ant $k$ in node $i$ choose node $j$ to move to, which is defined by,

$$
\begin{aligned}
& \eta_{i j}=\frac{1}{\left(f\left(x_{j}\right)-f\left(x_{i}\right)\right)} \\
& p_{i j}^{a}(t)=\left\{\begin{array}{cc}
\frac{\left[\tau_{i j}\right]^{\alpha}\left[\eta_{i j}\right]^{\beta}}{\sum_{n \in N^{a}\left[\tau_{i n}\right]^{\alpha}\left[\eta_{i n}\right]^{\beta}}} & \text { if } j \in N^{a} \\
0 ; & \text { otherwise }
\end{array}\right\}
\end{aligned}
$$

$\tau_{i j}^{a}$ : $\quad$ Pheromone amount deposited at $i j$ edge

$\alpha$ : $\quad$ Parameter to control influence of pheromone trace

$\beta$ : $\quad$ Parameter to control influence of visibility value

$N^{a}$ : All feasible nodes in neighborhood for $a$ ant

$$
p_{i j}^{a}(t)=\left\{\begin{array}{lc}
\frac{\left[\tau_{i j}^{a}\right]}{\sum_{n \in N^{a}\left[\tau_{i n}^{a}\right]} ;} & \text { if } j \in N^{a} \\
0 ; & \text { otherwise }
\end{array}\right\}
$$

\section{Optimization of FLC}

Optimization of FLC comprises of four steps, which are rule base optimization, scaling factors optimization, membership functions parameters optimization and rules weight optimization, respectively. ACO is used to find out optimum values in each step and IAE is selected as an objective function, as per eq. (7). Flow chart of ACO algorithm is shown in Fig. 6.

\subsubsection{Rule Base Optimization}

Good rule base is a major concern, when no human expert is available. Rule base is a collection of logic rules in the form of IF-THEN statements, where the IF part is called the "antecedent" and the THEN part is called the "consequent".

Rule Base optimization is to find the best possible consequent part corresponding to antecedent part, as shown in Fig. 7. ACO is utilized to find the consequent parts of rule base, where antecedent parts are all possible combinations. 


\subsubsection{Scaling Factor Optimization}

ACO is used to obtain the optimum value of scaling factor. In this paper, FLC having 2 inputs as well as 2 outputs, so 4 scaling factors for individual FLC controller and 8 scaling factors for both controllers need to be optimized.

After scaling factors optimization using ACO, as in Fig. 8, optimum values of scaling and gain parameters are shown in Table 3.

\subsubsection{Membership Functions parameters optimization}

Membership Function specifies the degree to which a given inputs belongs to set or a function that defines how each point in the input space is mapped to a degree of membership between 0 and 1. Only trapezoidal and triangular type MF's used here. These are mathematically defined by eq (14) and eq (15) respectively,

$$
\begin{aligned}
& f\left(x ; X_{L}, X_{C}, X_{R}\right)=\max \left(\min \left(\frac{x-X_{L}}{X_{C}-X_{L}}, \frac{X_{R}-x}{X_{R}-X_{C}}\right), 0\right) \\
& f\left(x ; X_{L}, X_{C L}, X_{C R}, X_{R}\right)=\max \left(\min \left(\frac{x-X_{L}}{X_{C L}-X_{L}}, 1, \frac{X_{R}-x}{X_{R}-X_{C R}}\right), 0\right)
\end{aligned}
$$

In this paper, corresponding to each variable 6 parameters are selected for optimization, as shown in

Fig. 9. Membership function distribution of each variable is symmetrical from zero, so either positive side parameters can be choosed or negative side parameters can be choosed for optimization, but due to symmmetrical structure all 12 pareameters will be optimized.

In this step, ACO is used for each variable’s membership functions's parameters optimization. All input as well as output variables' parameters of both FLC controllers optimized in this step, as shown in Fig.10.

\subsubsection{Rules Weight Optimization}

This fourth step of optimization is for selecting appropriate weight for individual rule in rule base. Default rule weight for all rule in FLC controller design selected as 1, but for a complex 
system putting all rules with unity gain is inappropriate. So, rule weights for all rules selected between 0.01 to 1 with 0.01 precision using ACO algorithm, as per Fig. 11.

Finally, after these four steps, the optimized controllers for both areas as shown in Fig. 12 and 13 were compared againest conventional PID controller and GA optimized PID controller.

\section{RESULTS \& DISCUSSION}

In this paper, optimized FLC Controller is used for both areas. New optimization approach is proposed for optimization of FLC. The optimization approach is executed in four steps using GA, the best fitness found after every iteration in these steps is shown in Fig. 14 (a)-(d) respectively. The dynamic performance of proposed controller is compared with ZN tuned PID and GA optimized PID controller. Frequency deviations of both areas and tie-line deviation after a sudden load change of 0.01 p.u. in each area to observe combined impact of thermal as well as hydro power system are shown in Fig. 15. Results show that ACO optimized FLC is more effective to damp out oscillations. In order to minimize frequency deviation and tie-line deviation the effect of SMES support is also examined with proposed controller, shown in Fig. 16. A comparative analysis is also carried out between AGC without SMES support with ZN tuned PID, GA optimized PID controller, ACO optimized FLC, GA optimized PID controller with SMES support and ACO optimized FLC with SMES support, as shown in Table 4.

\section{CONCLUSION}

This paper primarily focussed on an intelligent and optimized control solution for automatic generation control of interconnected power system. Three different controller designs are analysed for the given power system and simulation results are compared. The proposed technique is based on ant colony optimized fuzzy controller where fuzzy is optimized sequentially at four stages. Results justify that proposed optimized FLC provides a better performance compared to ZN tuned 
PID controller and GA optimized PID. Another source added in interconnected system is an energy storage device, SMES, which has unique feature of supporting active power to withstand heavy load disturbances. In smart grid environment, SMES has a major role to play in years to come for frequency stabilization in a complex power grid. The controllers are tested with and without SMES in place in system. The proposed controller with ACO shows appreciable performance over others in suppressing frequency of areas even when the disturbance has occurred in either of the area. Other results also strengthen the justification of implementing optimized intelligent controller for frequency stabilization in order to meet quality power demand. It may be concluded that proposed controller is able to achieve desired performance in present day power system.

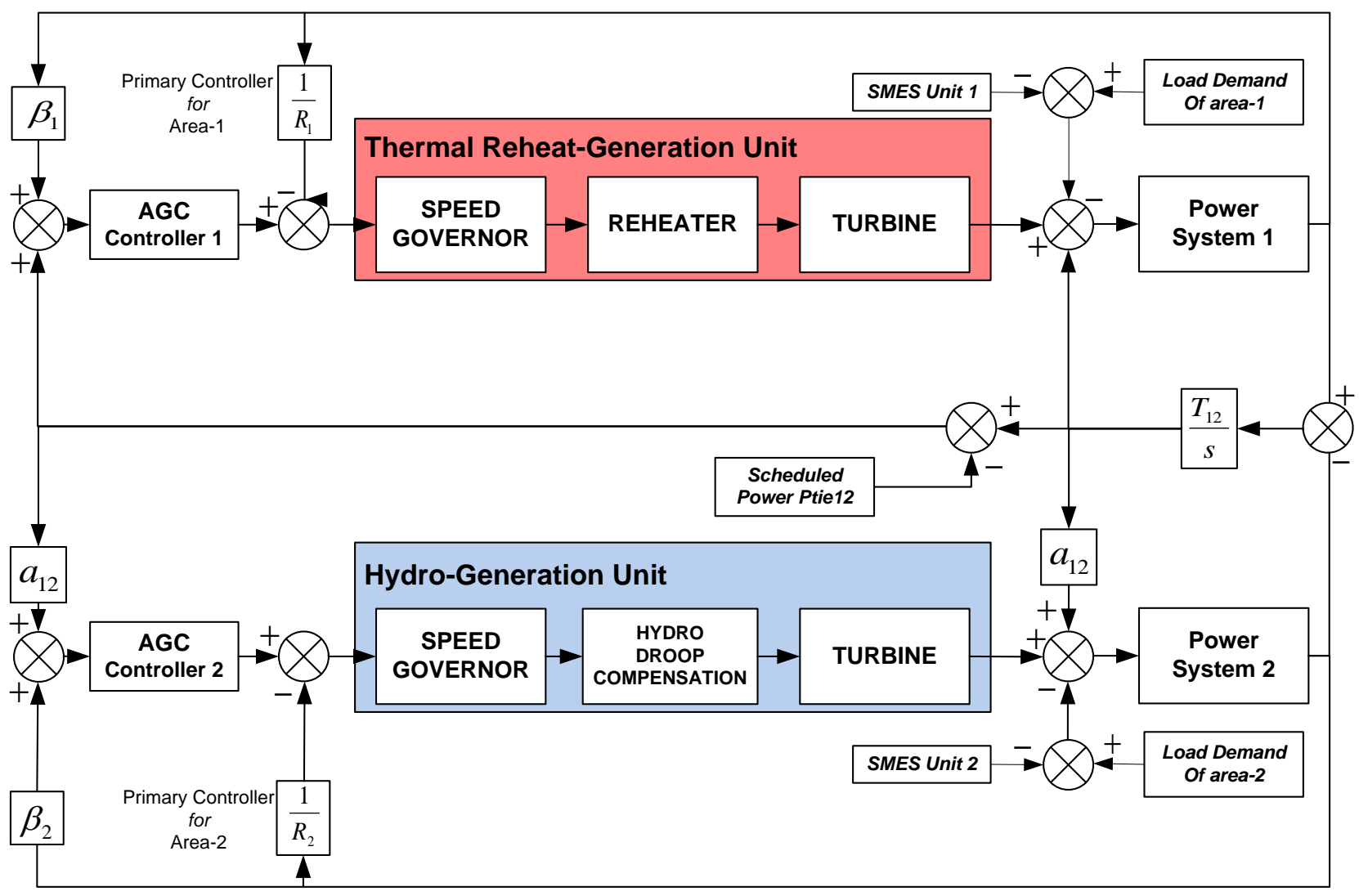

Figure 1. Complete System model of AGC of Two Area Thermal-Hydro Power System 


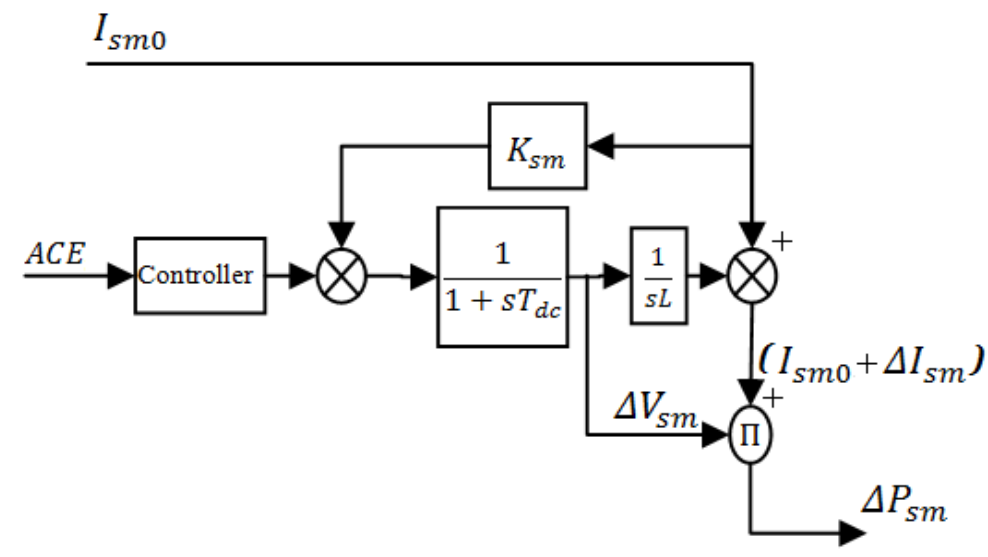

Figure 2. Block Diagram of SMES unit

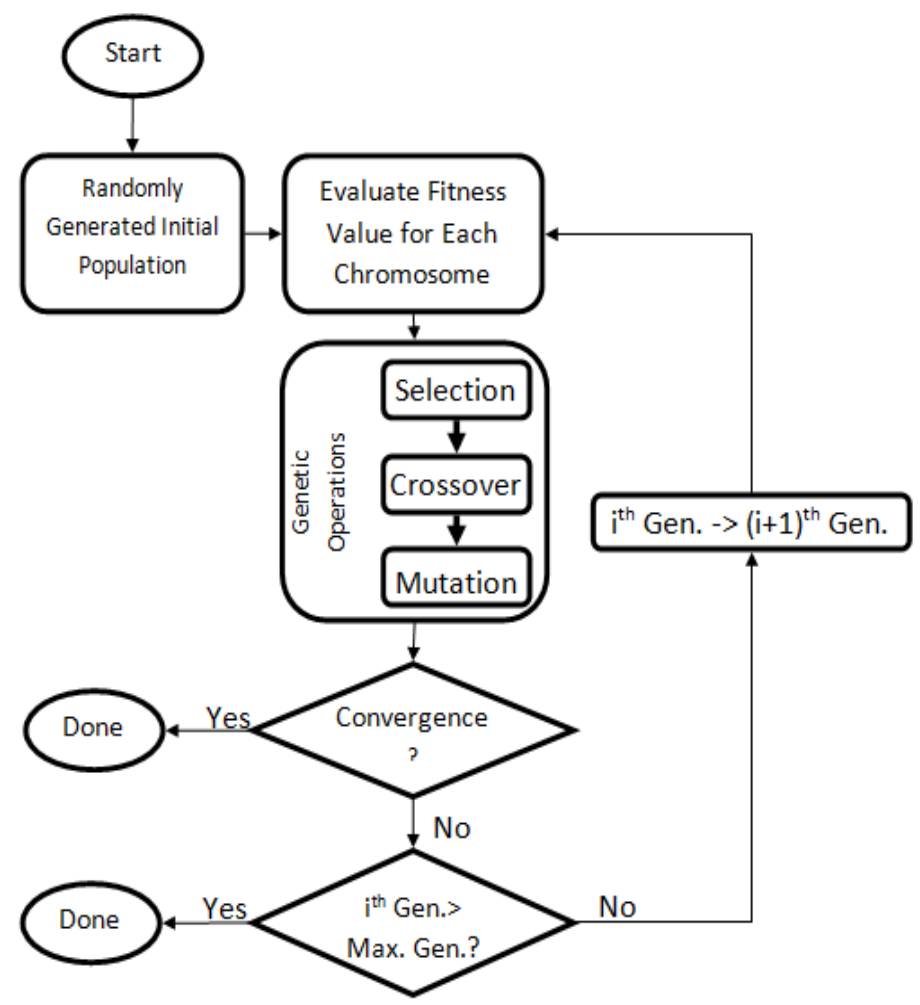

Figure 3. Flow chart of genetic algorithm

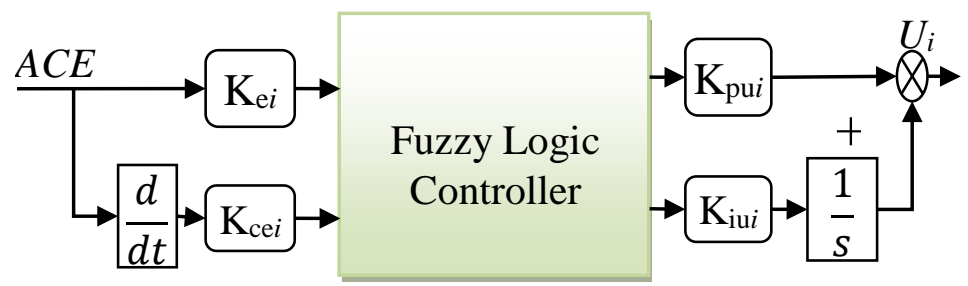

Figure 4. Fuzzy Logic Controller for i-Area, where i=1 \&2 


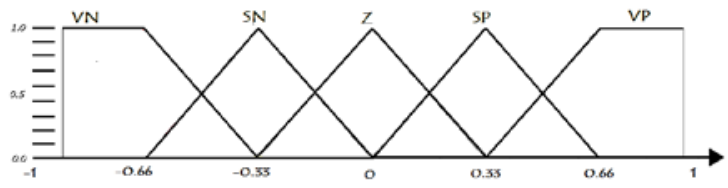

VN: Very Negative

SN: Small Negative

Z: Zero

SP: Small Positive

VP: Very Positive

Figure 5. Membership Functions for input and output variables

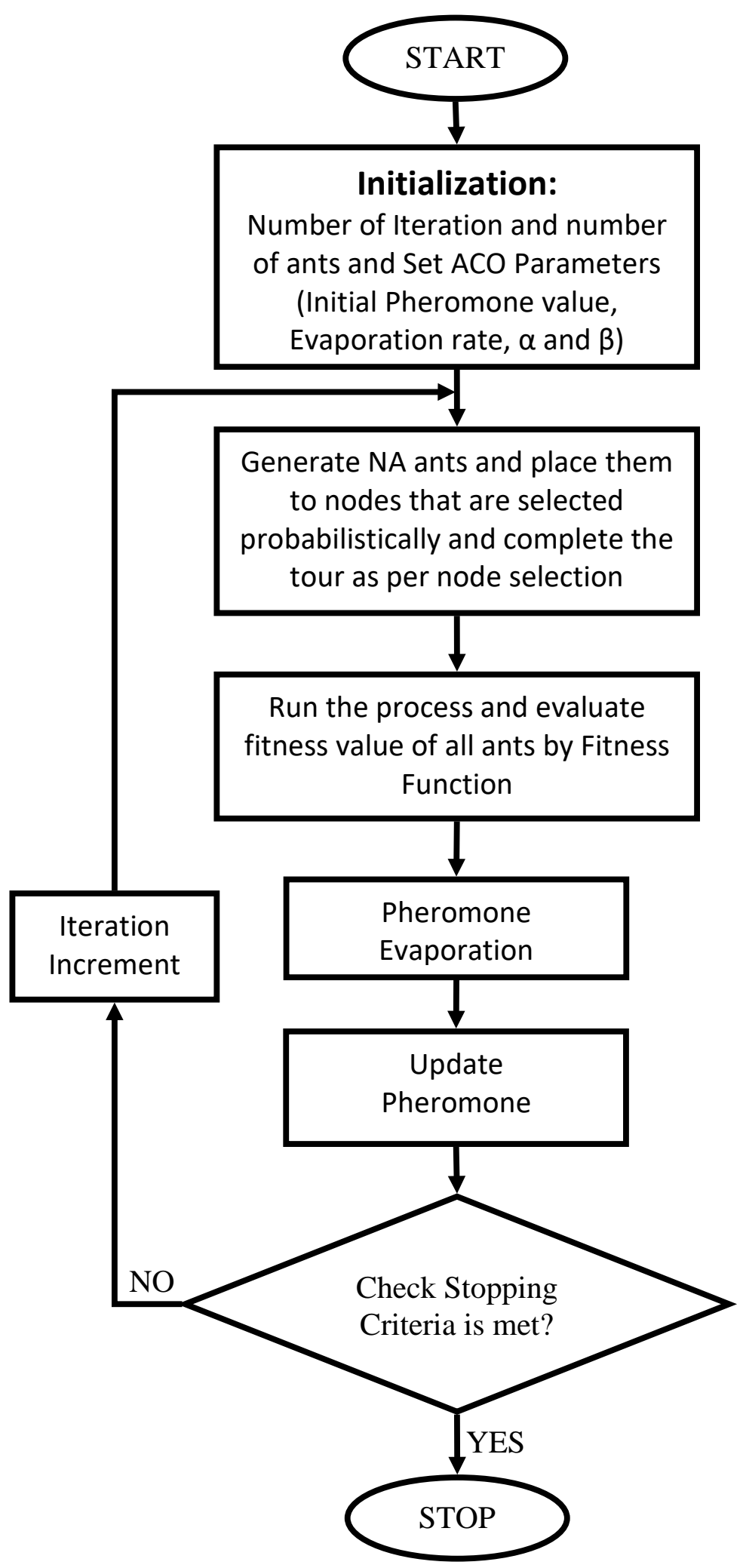

Figure 6. ACO flow chart 


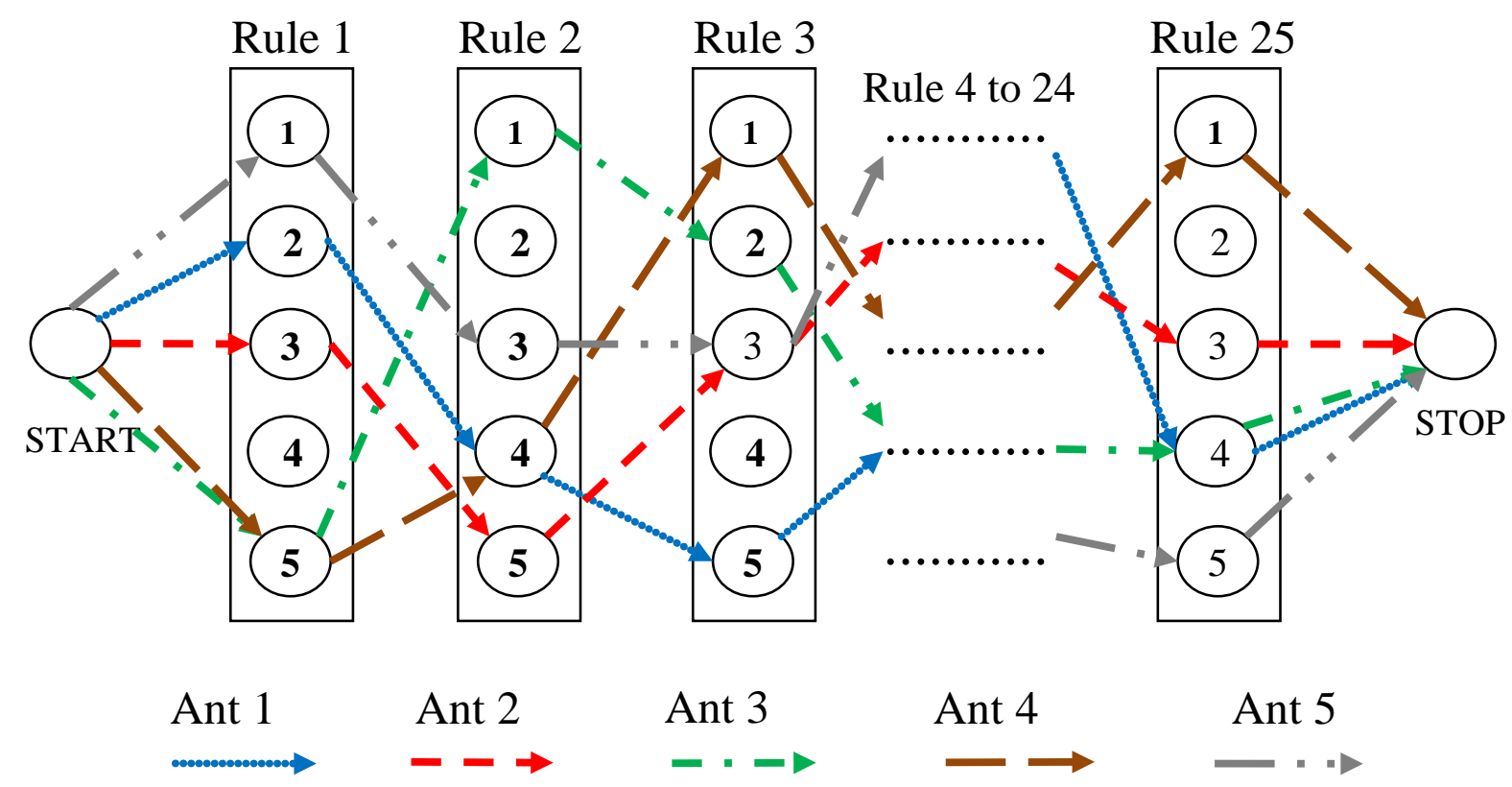

Figure 7. Rule Base Optimization

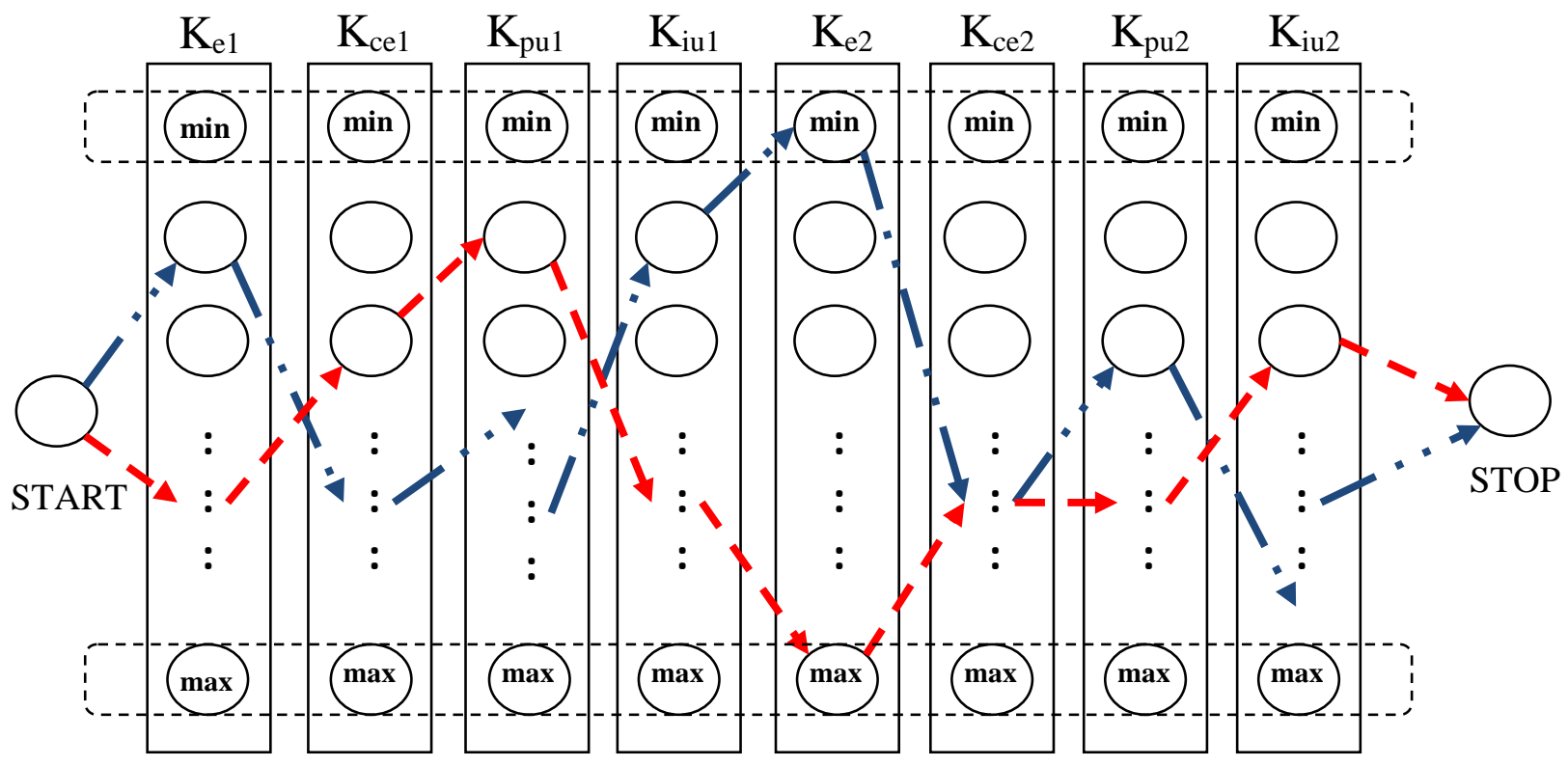

Ant $1-\cdots$

Ant a $--\rightarrow$

Figure 8. Scaling factor ACO Optimization 


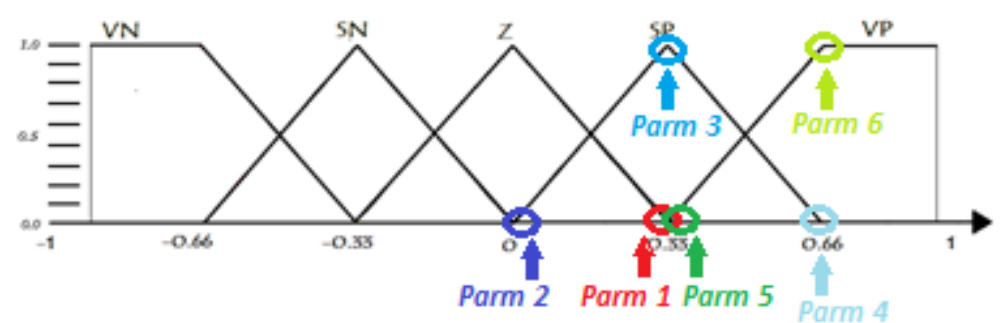

Figure 9. Each variable’s membership functions’s parameters for optimization

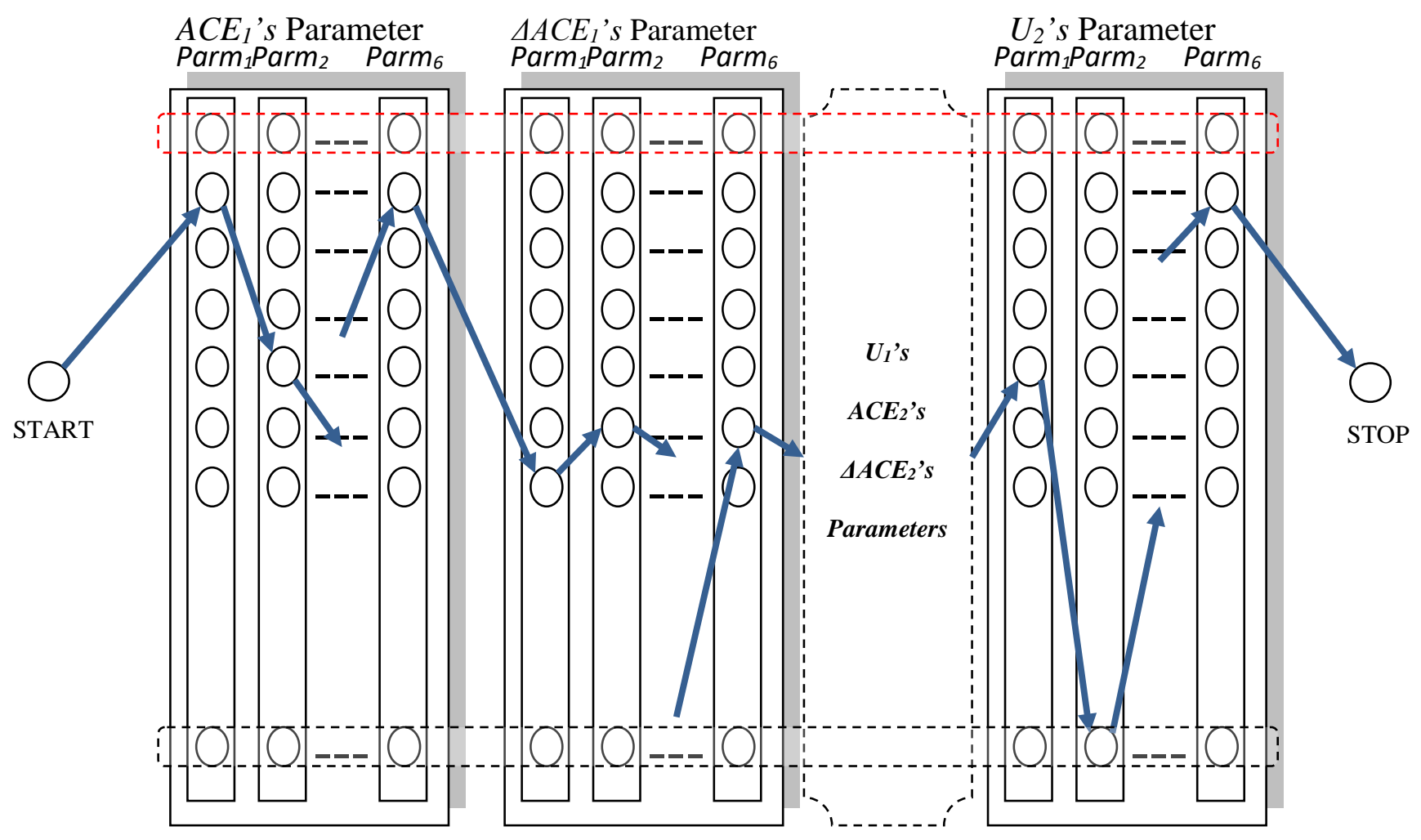

Figure 10. ACO for Membership function’s parameters optimization

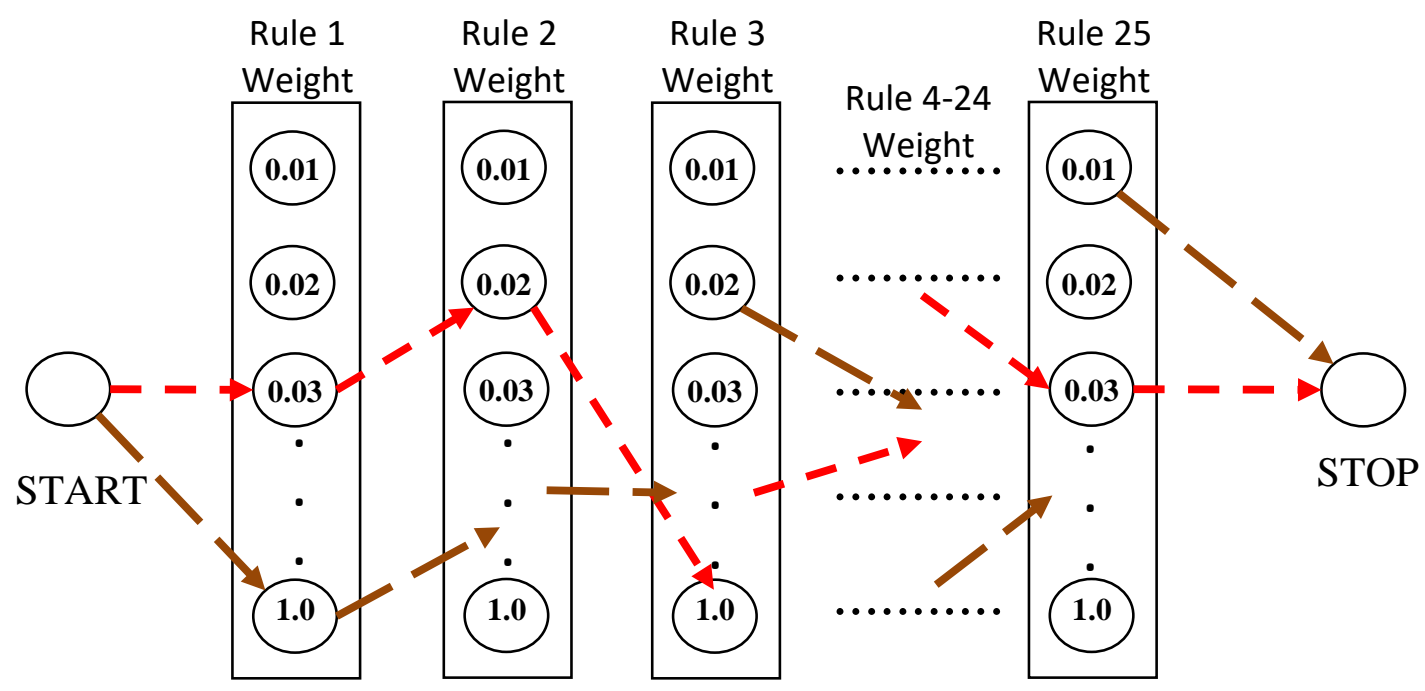

Ant $1 \quad-\quad \rightarrow \quad$ Ant k $\longrightarrow$

Figure 6 ACO for Rule Weight optimization 


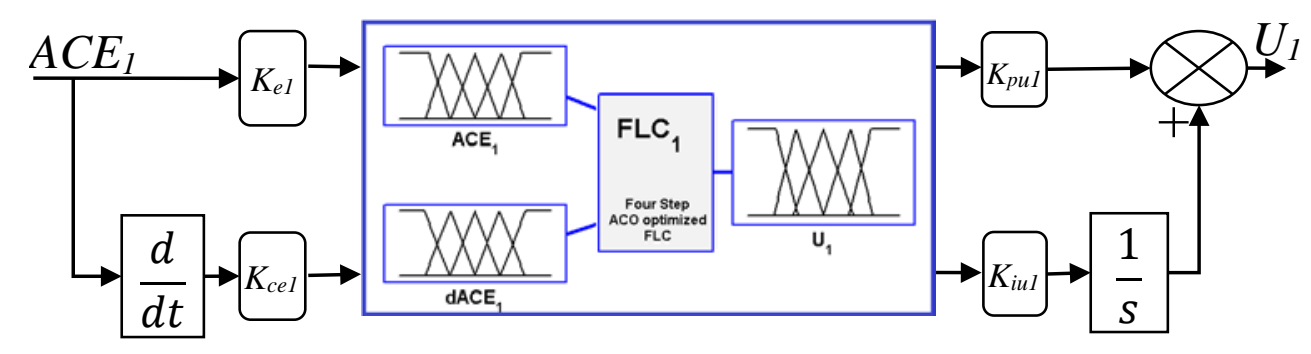

Figure 12. Four Step ACO optimized FLC for Area-1

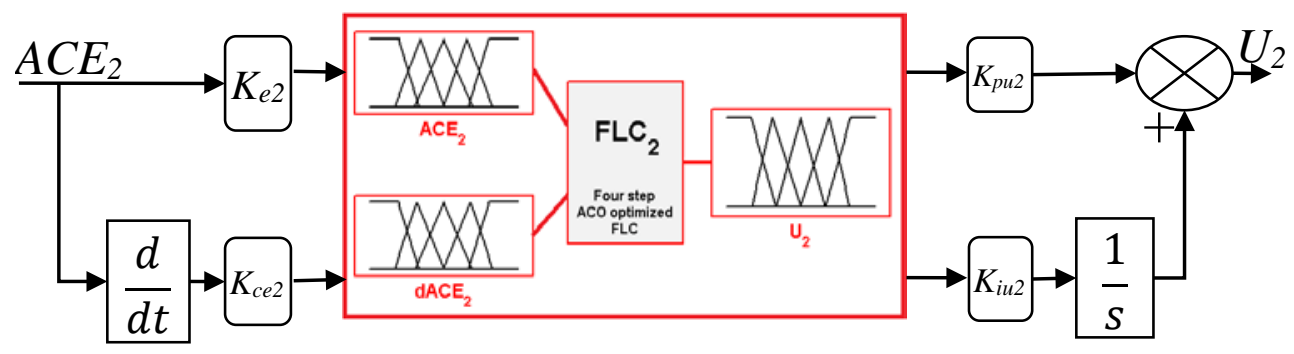

Figure 13. Four Step ACO optimized FLC for Area-2

Fitness Value vs Iteration

Best Fitness 342.70

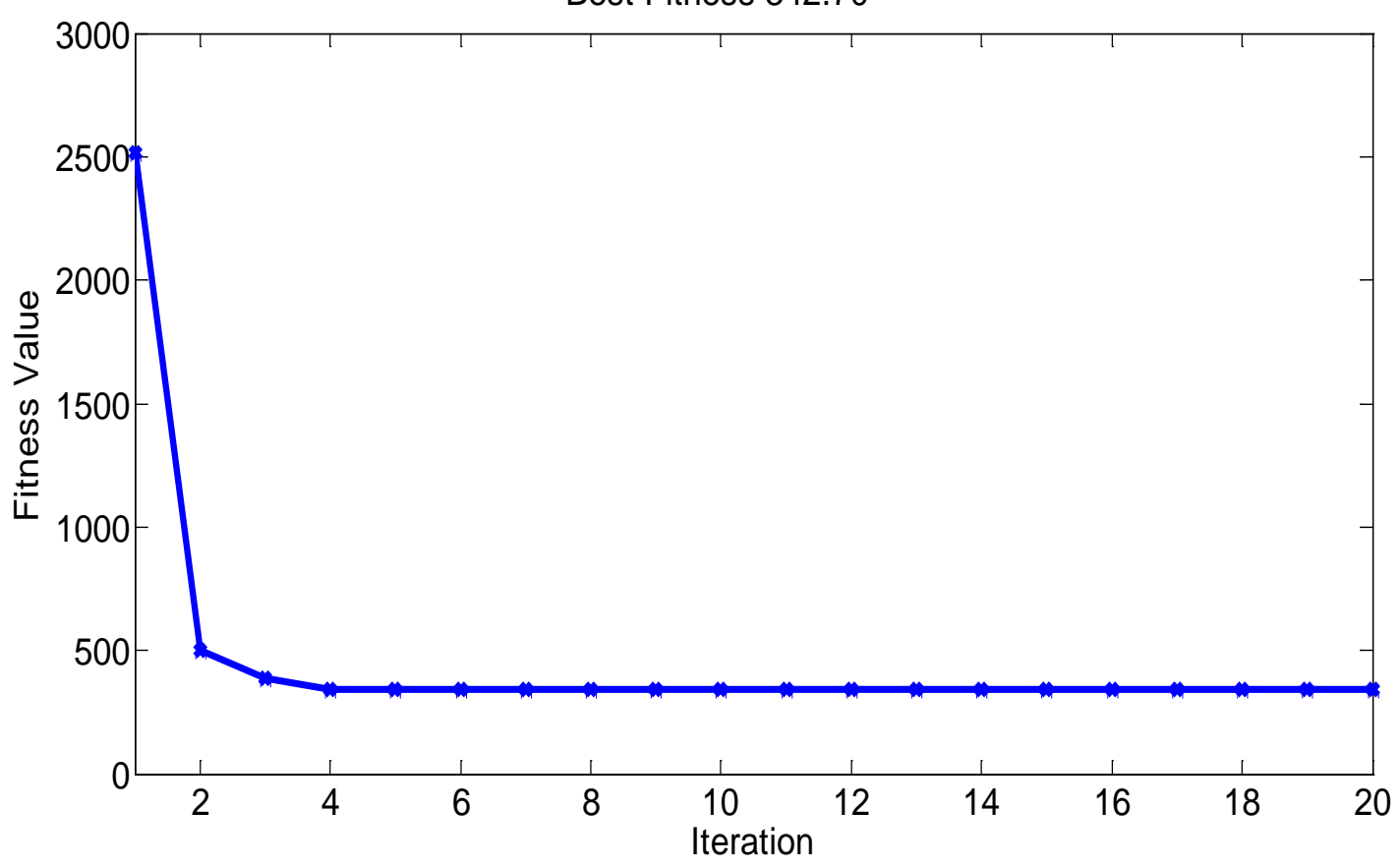

(a) 
Fitness Value vs Iteration

Best Fitness 69.22

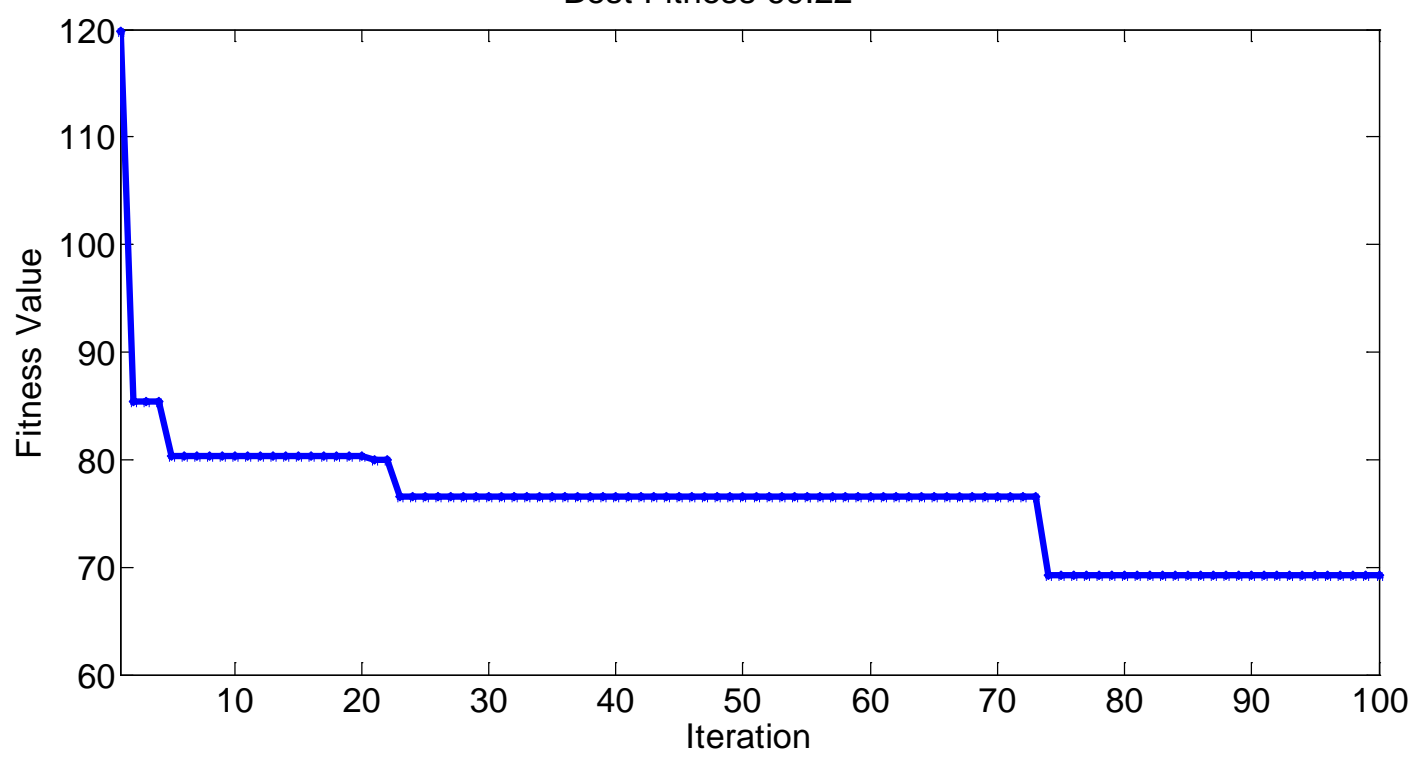

(b)

Fitness Value vs Iteration

Best Fitness 61.32

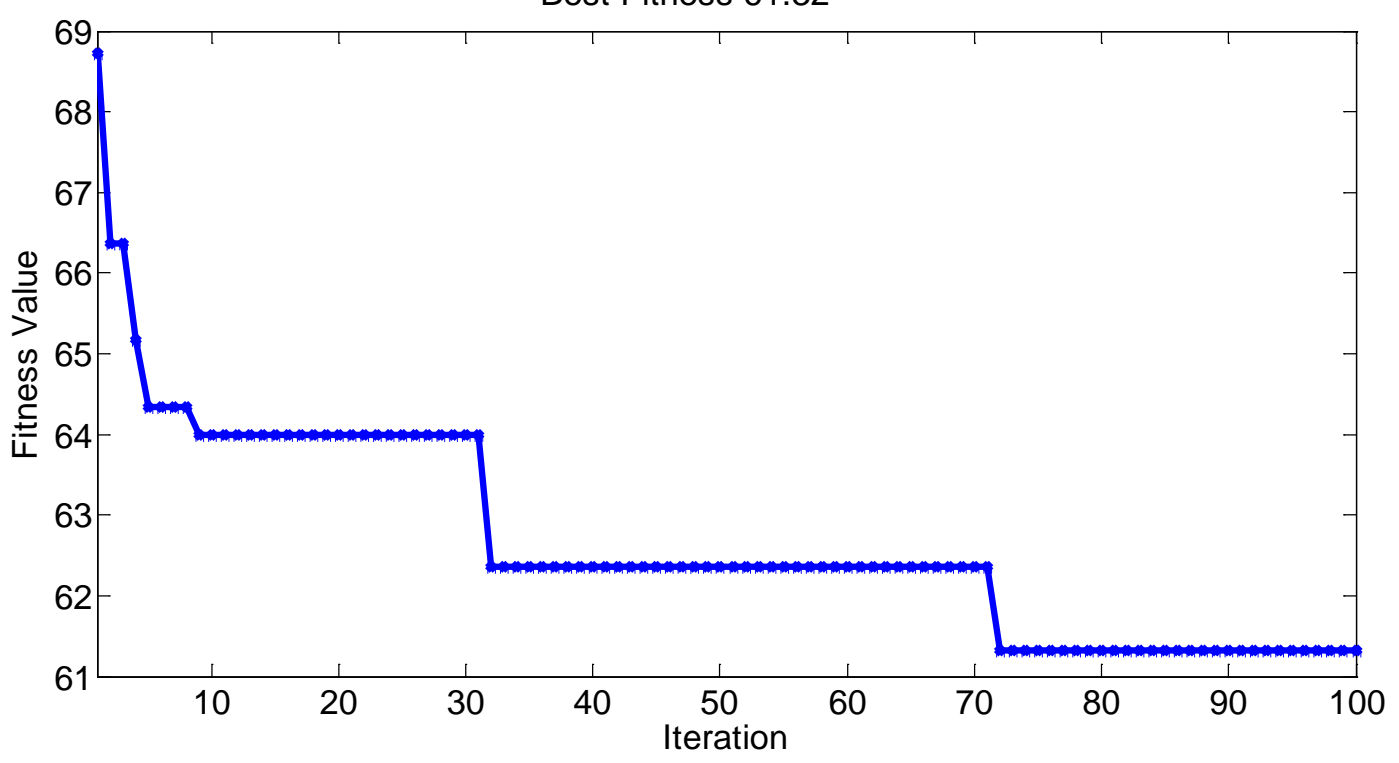

(c) 


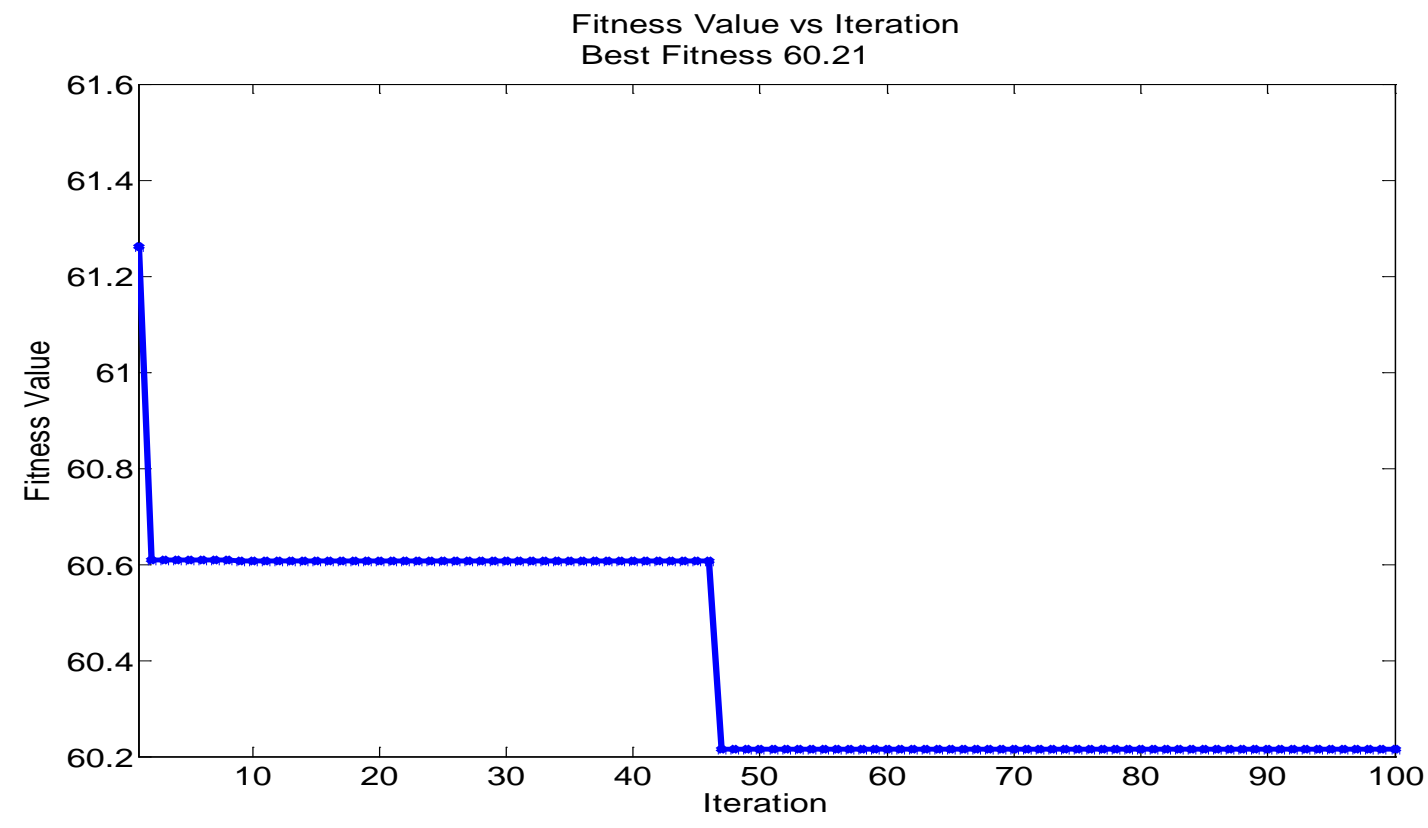

(d)

Figure 74. Best fitness value after each iteration for ACO algorithm for optimization of rule base of FLC (b) scaling and gain parameters of FLC (c) MF's parameters of FLC (d) rules weighting factor of FLC

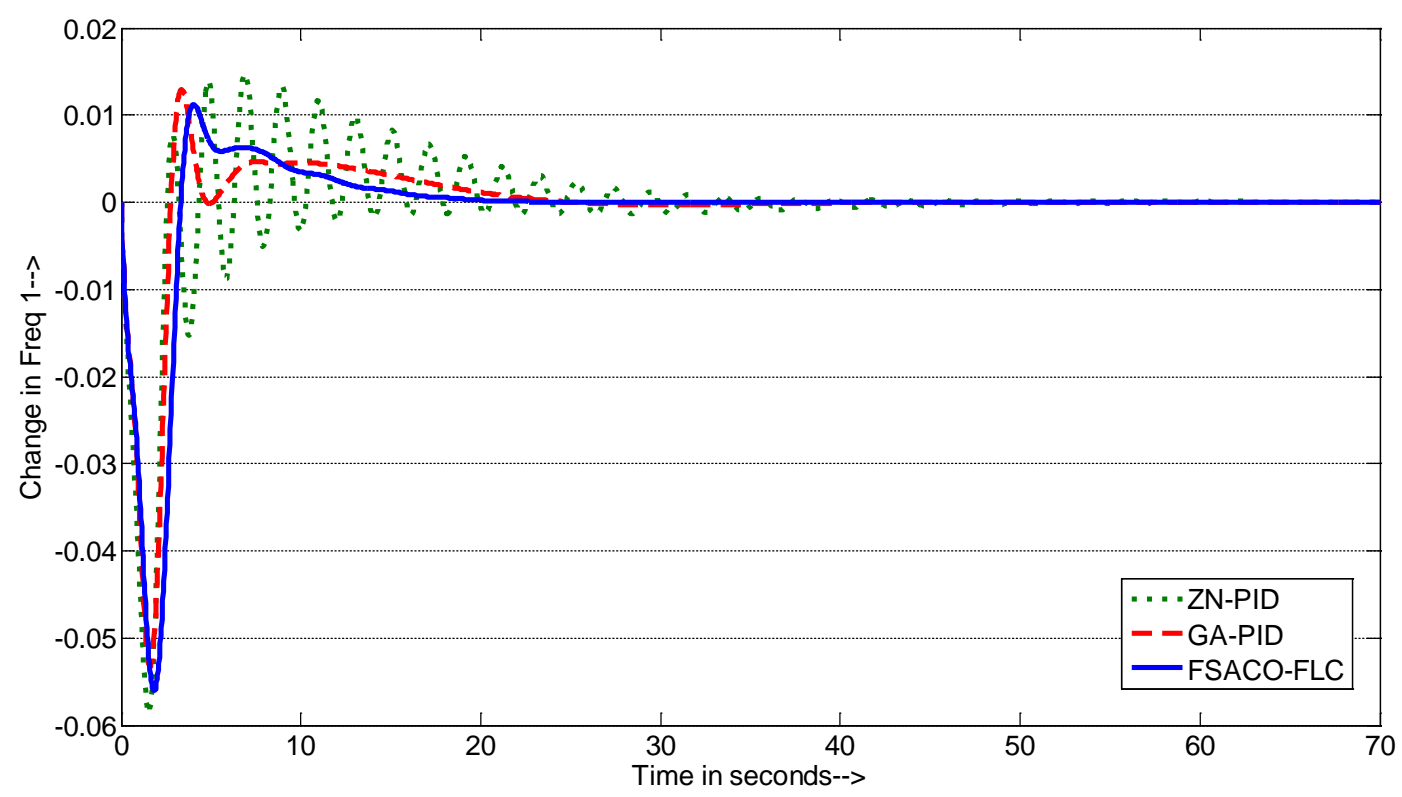

(a) 


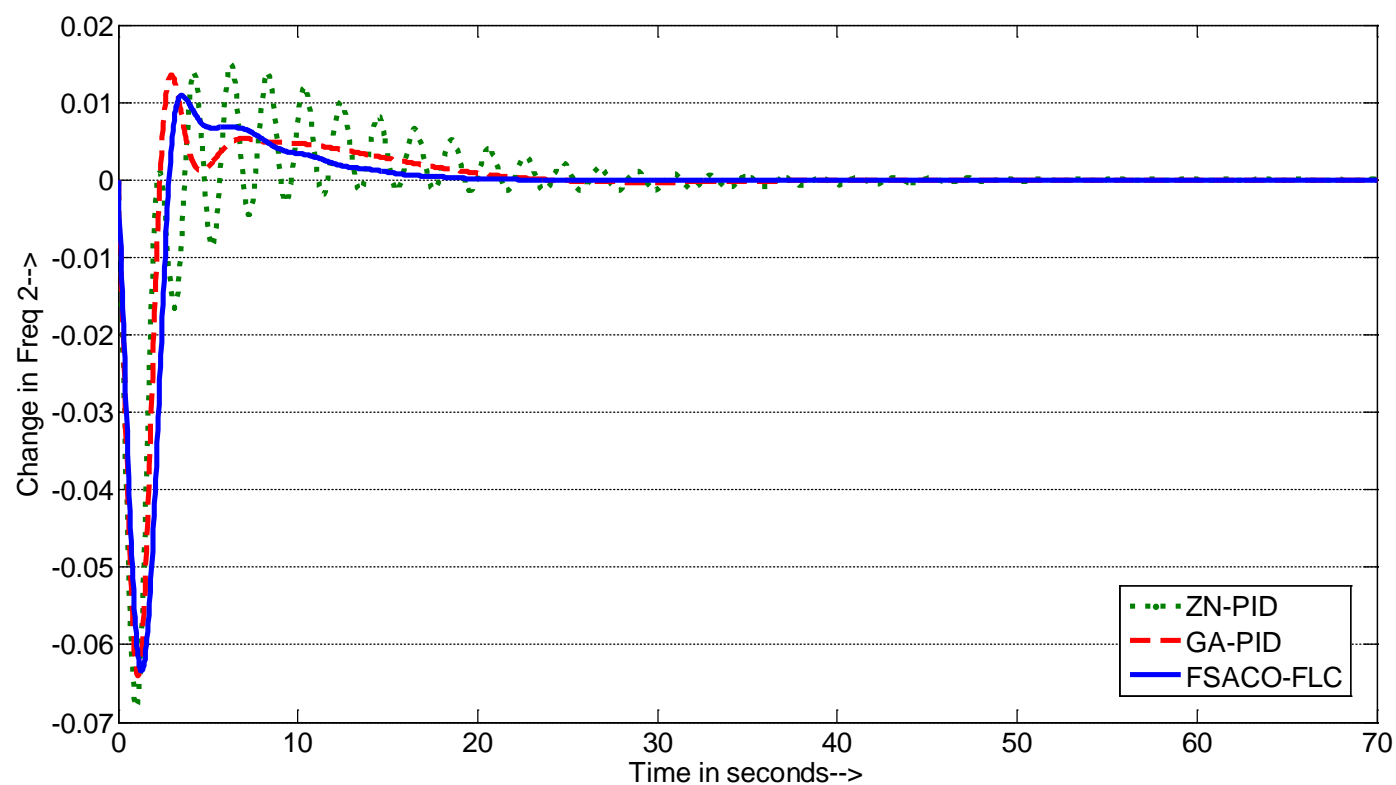

(b)

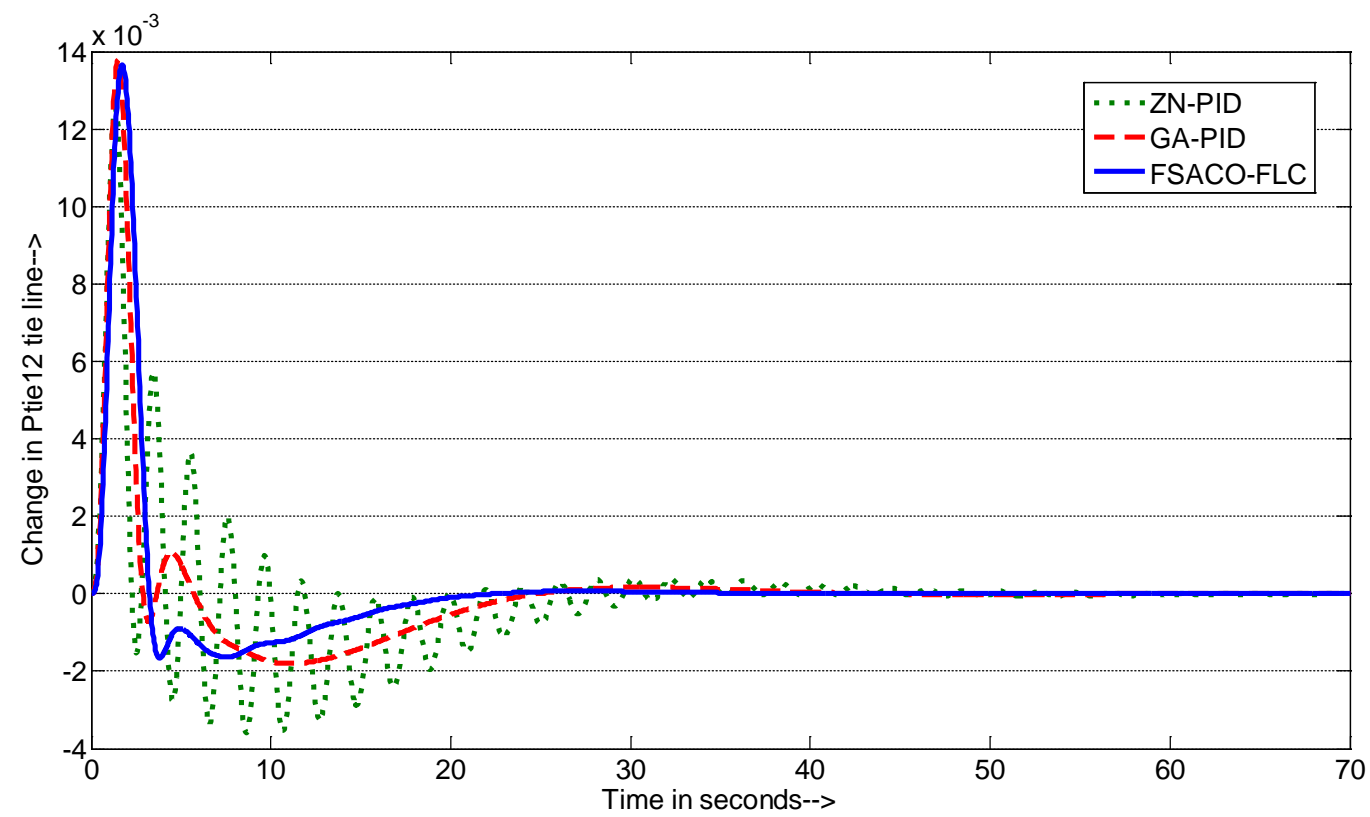

(c)

Figure 85. Comparison of ZN tuned PID, GA optimized PID and ACO optimized FLC for two area thermal-hydro power system (a) $\Delta \mathrm{f} 1$, (b) $\Delta \mathrm{f} 2$, (c) $\Delta$ Ptie12 


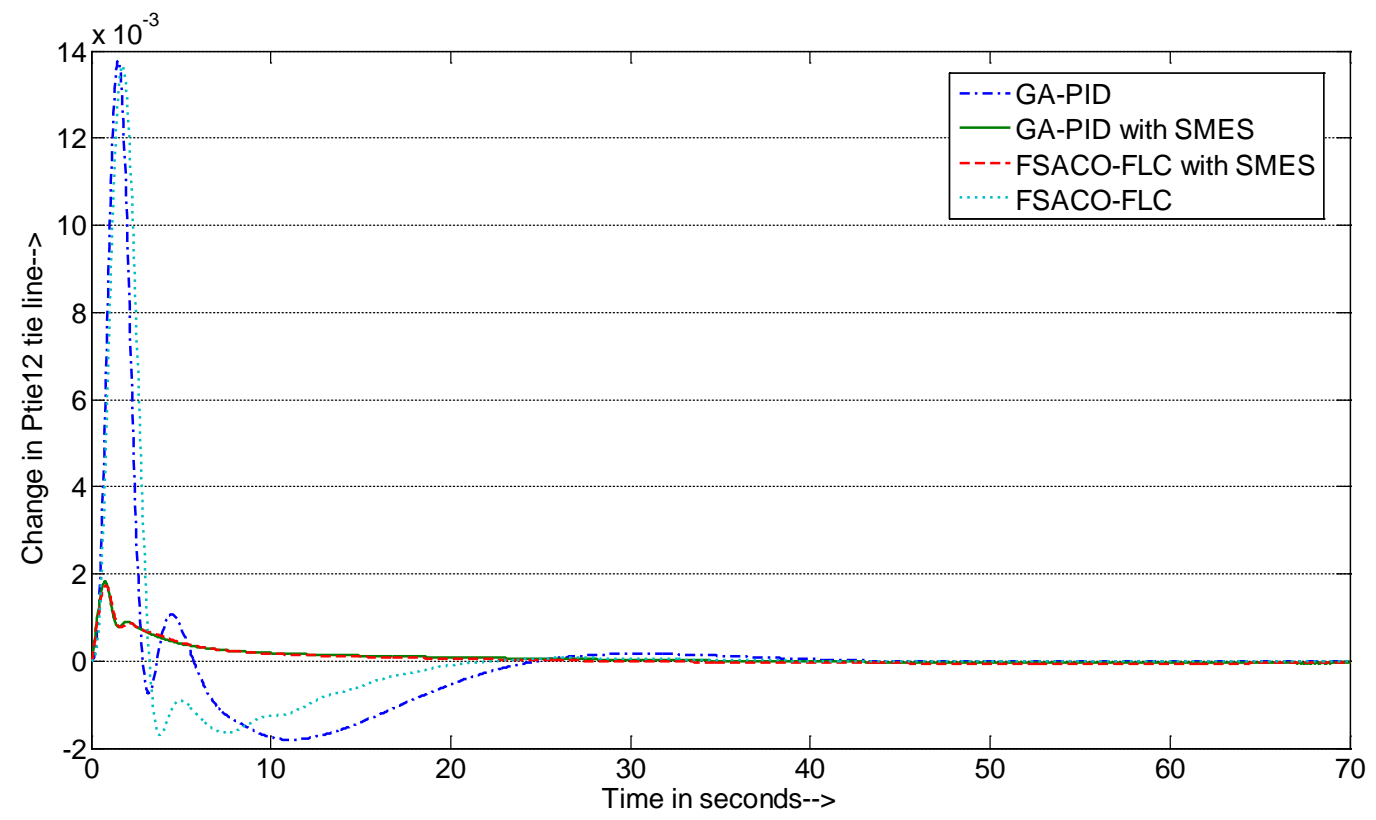

(a)

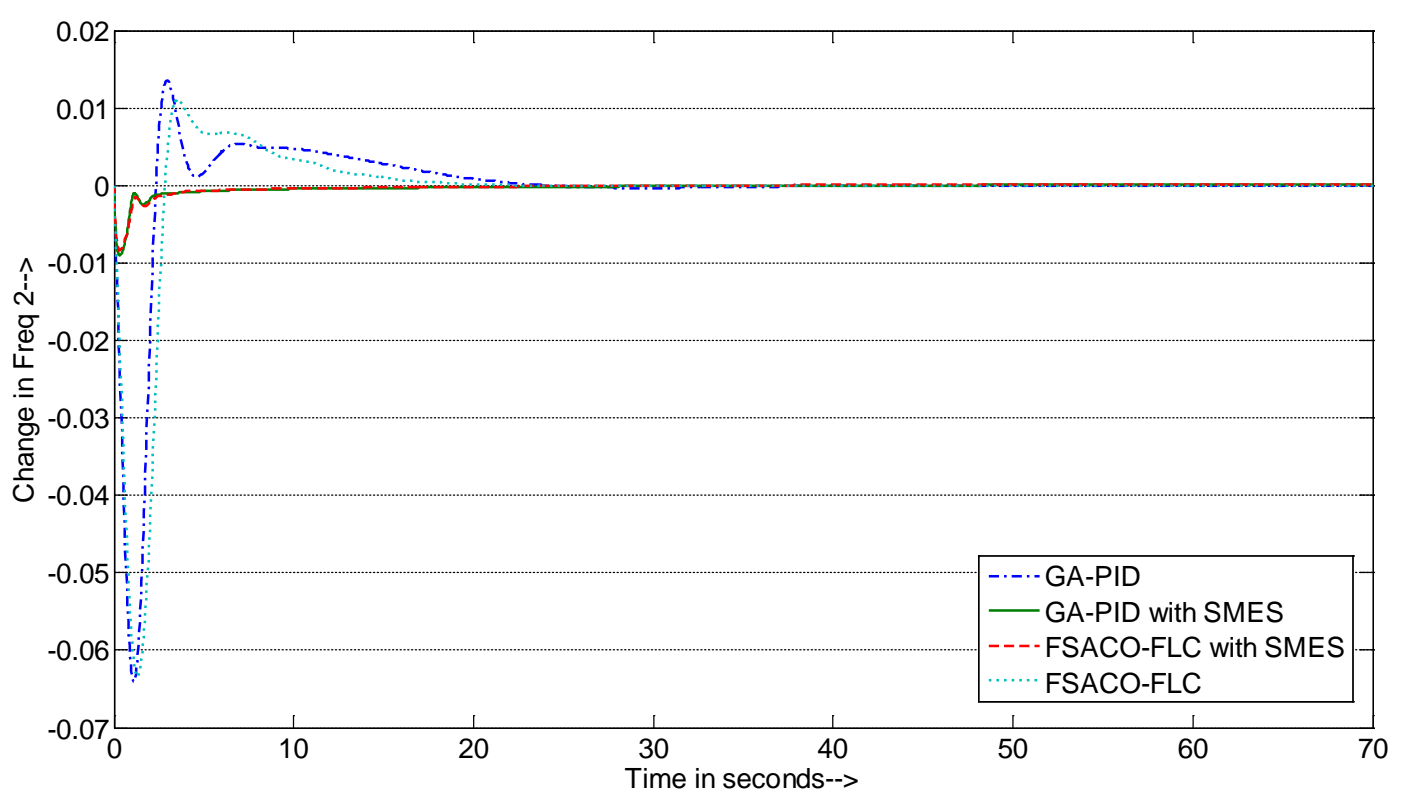

(b) 


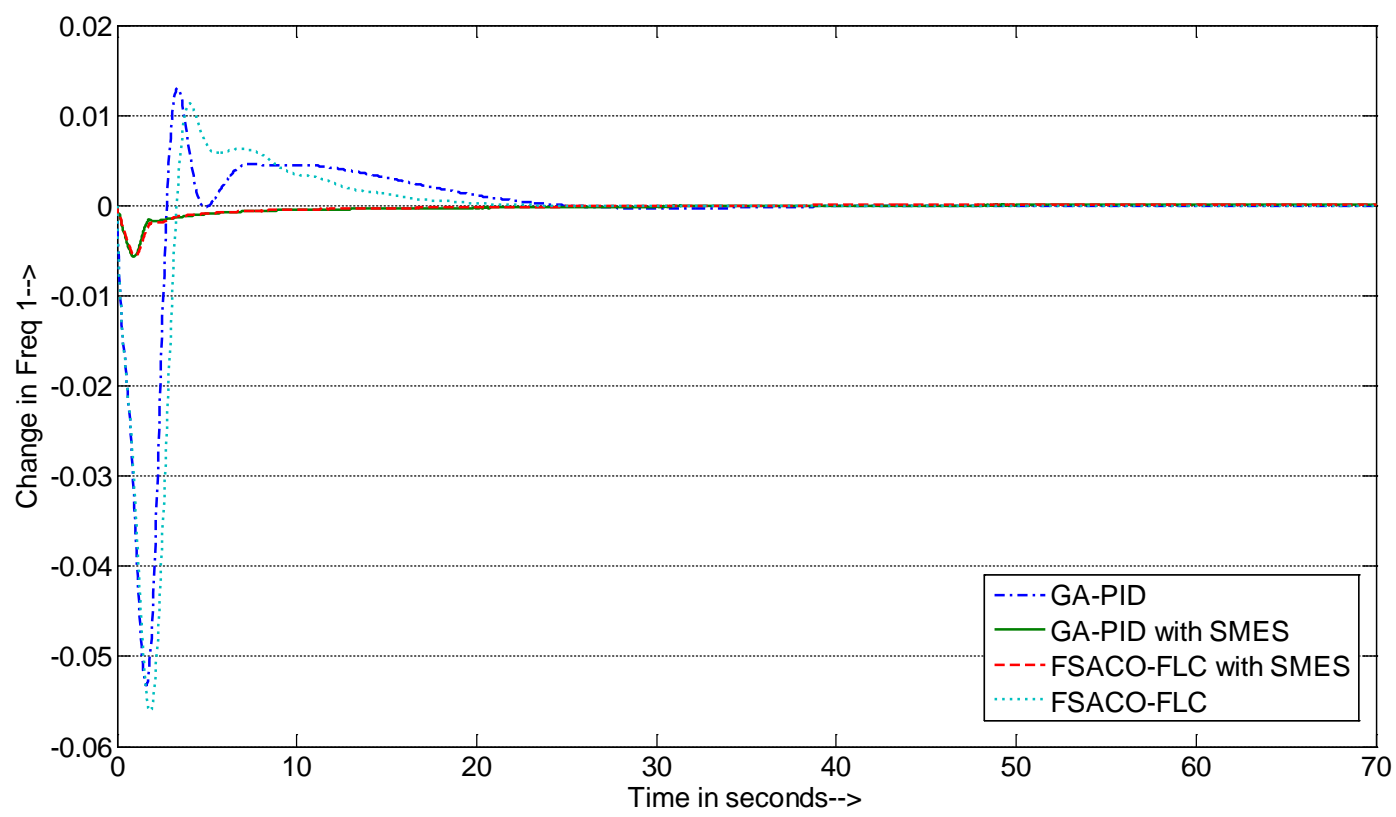

(c)

Figure 16. Comparison of AGC with GA optimized PID, GA optimized PID with SMES support, ACO optimized FLC with SMES support and ACO optimized FLC without SMES support (a) $\Delta \mathrm{f} 1$, (b) $\Delta \mathrm{f} 2$, (c) $\Delta \mathrm{Ptie} 12$

Table 1. PID Controller Gains from ZN tuning method

\begin{tabular}{|c|c|c|c|}
\hline Area-1 & $\mathbf{K}_{\mathbf{p} 1}$ & $\mathbf{K}_{\mathbf{i} 1}$ & $\mathbf{K}_{\mathbf{d} 1}$ \\
\cline { 2 - 4 } PID Controller Gains & 1.074 & 0.74 & 0.389 \\
\hline Area-2 & $\mathbf{K}_{\mathbf{p} 2}$ & $\mathbf{K}_{\mathbf{i} 2}$ & $\mathrm{~K}_{\mathrm{d} 2}$ \\
\cline { 2 - 4 } PID Controller Gains & 1.074 & 0.74 & 0.389 \\
\hline
\end{tabular}

Table 2. PID Controller gains from GA optimization method

\begin{tabular}{|c|c|c|c|}
\hline Area-1 & $\mathbf{K}_{\mathbf{p} 1}$ & $\mathbf{K}_{\mathbf{i} 1}$ & $\mathbf{K}_{\mathbf{d} 1}$ \\
\cline { 2 - 4 } PID Controller Gains & 1.6823 & 1.44188 & 0.66441 \\
\hline \multirow{2}{*}{ Area-2 } & $\mathbf{K}_{\mathbf{p} 2}$ & $\mathbf{K}_{\mathbf{i} 2}$ & $\mathrm{~K}_{\mathrm{d} 2}$ \\
\cline { 2 - 4 } & 0.770119 & 0.891877 & 0.165158 \\
\hline
\end{tabular}


Table 3. Optimum Value of Scaling and Gain Parameters

\begin{tabular}{|l|c|c|c|c|}
\hline & \multicolumn{2}{|c|}{ Scaling Parameters } & \multicolumn{2}{c|}{ Gain Parameters } \\
\hline \multirow{2}{*}{ FLC for Area-1 } & $K_{e 1}$ & $K_{c e 1}$ & $K_{p u 1}$ & $K_{i u 1}$ \\
\cline { 2 - 5 } & 3.42 & 0.74 & 1.01 & 0.79 \\
\hline \multirow{2}{*}{ FLC for Area-2 } & $\boldsymbol{K}_{\boldsymbol{e} 2}$ & $\boldsymbol{K}_{\boldsymbol{c} e 2}$ & $\boldsymbol{K}_{p u 2}$ & $\boldsymbol{K}_{\text {iu2 }}$ \\
\cline { 2 - 5 } & 0.68 & 0.48 & 0.02 & 0.44 \\
\hline
\end{tabular}

Table 4 Comparison of Performance Indices of $\Delta \mathrm{f} 1, \Delta \mathrm{f} 2$ and $\Delta \mathrm{Ptie} 12$ for different control strategies

\begin{tabular}{|c|c|c|c|c|c|c|}
\hline & & $\begin{array}{l}\text { ZN tuned } \\
\text { PID } \\
\text { Controller }\end{array}$ & $\begin{array}{c}\text { GA } \\
\text { optimized } \\
\text { PID } \\
\text { Controller }\end{array}$ & $\begin{array}{c}\text { Four Step } \\
\text { ACO } \\
\text { optimized } \\
\text { FLC }\end{array}$ & $\begin{array}{l}\text { GA optimized } \\
\text { PID Controller } \\
\text { with SMES }\end{array}$ & $\begin{array}{c}\text { Four Step } \\
\text { ACO } \\
\text { optimized FLC } \\
\text { with SMES }\end{array}$ \\
\hline \multirow{3}{*}{$\begin{array}{l}\text { Peak } \\
\text { Under } \\
\text { Shoot }\end{array}$} & $\begin{array}{l}\text { Frequency } \\
\text { of Area-1 }\end{array}$ & 0.058541 & 0.053201 & 0.056051 & 0.005697 & 0.005582 \\
\hline & $\begin{array}{c}\text { Frequency } \\
\text { of Area-2 }\end{array}$ & 0.068018 & 0.064058 & 0.063395 & 0.008988 & 0.008376 \\
\hline & $\begin{array}{l}\text { Tie-line } \\
\text { Power }\end{array}$ & 0.003592 & 0.001806 & 0.001668 & 0.000051 & 0.000056 \\
\hline \multirow{3}{*}{$\begin{array}{l}\text { Settling } \\
\text { Time } \\
( \pm 5 \%)\end{array}$} & $\begin{array}{c}\text { Frequency } \\
\text { of Area-1 }\end{array}$ & 42.799698 & 22.262673 & 18.256394 & 9.461172 & 8.942873 \\
\hline & $\begin{array}{c}\text { Frequency } \\
\text { of Area-2 }\end{array}$ & 40.301705 & 21.305733 & 17.070604 & 8.537585 & 7.770874 \\
\hline & $\begin{array}{c}\text { Tie-line } \\
\text { Power }\end{array}$ & 27.160380 & 20.210720 & 15.517784 & 4.042878 & 4.391309 \\
\hline
\end{tabular}




\section{REFERENCES}

[1] D. Wu, K. T. Chau, C. Liu, S. Gao, and F. Li, “Transient stability analysis of SMES for smart grid with vehicle-to-grid operation,” IEEE Trans. Appl. Supercond., vol. 22, no. 3, 2012, p. 5701105.

[2] Arya, Y., and Kumar, N., "Fuzzy gain scheduling controllers for AGC of two-area interconnected electrical power systems,” Elect. Power Compon. Syst., Vol. 44, No. 7, April 2016, pp. 737-751.

[3] Arya, Y., and Kumar, N., "Design and analysis of BFOA-optimized fuzzy PI/PID controller for AGC of multi-area traditional/restructured electrical power systems,” Soft Comput., DOI: 10.1007/s00500-016-2202-2, June 2016.

[4] Arya, Y., and Kumar, N., "BFOA-scaled fractional order fuzzy PID controller applied to AGC of multi-area multi-source electric power generating systems,” Swarm Evolution. Comput., DOI: 10.1016/j.swevo.2016.08.002, August 2016.

[5] S. Panda and N. K. Yegireddy, “Automatic generation control of multi-area power system using multi-objective non-dominated sorting genetic algorithm-II,” Int. J. Electr. Power Energy Syst., vol. 53, 2013, pp. 54-63.

[6] A. Yazdizadeh, M. H. Ramezani, and E. Hamedrahmat, "Decentralized load frequency control using a new robust optimal MISO PID controller,” Int. J. Electr. Power Energy Syst., vol. 35, no. 1, Feb. 2012,pp. 57-65.

[7] Bahgaat, N. K., El-Sayed, M. I., Hassan, M. M., \& Bendary, F. A. Load frequency control in power system via improving PID controller based on particle swarm optimization and ANFIS techniques. Research Methods: Concepts, Methodologies, Tools, and Applications: Concepts, Methodologies, Tools, and Applications, 2015, pp. 462. 
[8] S. Prakash and S. K. Sinha, "Load frequency control of three area interconnected hydrothermal reheat power system using artificial intelligence and PI controllers,” International Journal of Engineering, Science and Technology, vol. 4, no. 1, 2012, pp. 23-37.

[9] R. C. Bansal, "Bibliography on the Fuzzy Set Theory Applications to Power Systems (19942001)”, IEEE Trans. Power Systems, Vol. 18, No. 4, 2003, pp. 1291-1299.

[10] R. Farhangi, M. Boroushaki, and S. Hamid, "Load-frequency control of interconnected power system using emotional learning-based intelligent controller,” Int. J. Electr. Power Energy Syst., vol. 36, no. 1, 2012, pp. 76-83.

[11] E. S. Ali, "Bacteria foraging optimization algorithm based load frequency controller for interconnected power system,” Int. J. Electr. Power Energy Syst., vol. 33, no. 3, 2011,pp. 633-638.

[12] S. Panda, B. Mohanty, and P. K. Hota, "Hybrid BFOA-PSO algorithm for automatic generation control of linear and nonlinear interconnected power systems,” Appl. Soft Comput., vol. 13, no. 12, Dec. 2013, pp. 4718-4730.

[13] U. K. Rout, R. K. Sahu, and S. Panda, "Design and analysis of differential evolution algorithm based automatic generation control for interconnected power system,” Ain Shams Eng. J., vol. 4, no. 3, Sep. 2013, pp. 409-421.

[14] R. Roy and S. P. Ghoshal, "Evolutionary computation based optimization in fuzzy automatic generation control," in Third International Conference on Power Systemss, Kharagpur, INDIA, 2009, pp. 1-6.

[15] Ali, Ali M., M. A. Ebrahim, and MA Moustafa Hassan. "Automatic Voltage Generation Control for Two Area Power System Based on Particle Swarm Optimization." Indonesian Journal of Electrical Engineering and Computer Science, vol. 2, no. 1, 2016, pp. 132-144.

[16] Fakhry, A. M., M. E. Ammar, and MA Moustafa Hassan. "Two Area Load Frequency Control Based On Evolutionary Computational Techniques."; MEPCON 2015, Mansoura Uni., Egypt, Dec 2015. 
[17] Bahgaat, Naglaa K., et al. "Load Frequency Control Based on Evolutionary Techniques in Electrical Power Systems." Advances in Chaos Theory and Intelligent Control. Springer International Publishing, 2016, pp. 851-873.

[18] P. Kundur, Power System Stability and Control, vol. 23. New York: McGraw-Hill, 2006, p. 739.

[19] S. C. Tripathy, "Sampled Data Automatic Generation Control with Superconducting Magnetic Energy Storage in Power Systems", IEEE Transactions on Energy Conversion, vol. 12, no. 2, 1997, pp. 187-192.

[20] M. R. I. Sheikh, S. M. Muyeen, R. Takahashi, T. Murata, and J. Tamura, "Improvement of Load Frequency Control With Fuzzy Gain Scheduled SMES Unit Considering Governor Dead-Band and GRC,” 5th International Conference on Electrical and Computer Engineering, 2008, Dhaka, Bangladesh, 2008, pp. 20-22.

[21] J. G. Ziegler and N. B. Nichols, “Optimum Settings for Automatic Controllers,” Trans. A.S.M.E., vol. 65, no. 5, 1942, pp. 433-444.

[22] D. E. Goldberg, Genetic Algorithms in Search, Optimization, and Machine Learning, vol. Addison-We. 1989, pp. 432.

[23] Y. K. Bhateshvar, H. D. Mathur, H. Siguerdidjane, and S. Bhanot, "Frequency Stabilization for Multi-area Thermal-Hydro Power System Using Genetic Algorithm-optimized Fuzzy Logic Controller in Deregulated Environment,” Electr. Power Components Syst., vol. 43, no. March 2015, pp. 146-156.

[24] Y. K. Bhateshvar and H. D. Mathur, "Comparative Dynamic Analysis on Frequency Stabilization for Multi-Area power system in Deregulated Environment,” in 2012 IEEE International Conference on Signal Processing, Computing and Control (ISPCC), 2012, pp. $1-6$.

[25] H. D. Mathur, L. B. F. Leite, H. Siguerdidjane, and Y. K. Bhateshvar, "Study of impact of wind power penetration on frequency stabilization in multi-area power system,” in 2013 8Th 
International Symposium on Advanced Topics in Electrical Engineering (Atee), 2013, pp. 16.

[26] M. Dorigo and T. Stützle, Ant Colony Optimization. 2004, pp. 1-16.

[27] C. Juang and P. Chang, "Designing fuzzy-rule-based systems using continuous ant-colony optimization,” IEEE Trans. Fuzzy Syst., vol. 18, no. 1, 2010, pp. 138-149.

\section{APPENDIX:}

\section{Transfer function of different components:}

Speed Governor: $\frac{1}{\left(1+s T_{g}\right)}$;

Thermal Reheater: $\frac{\left(1+K_{r} s T_{r}\right)}{\left(1+s T_{r}\right)}$;

Thermal Turbine: $\frac{1}{\left(1+s T_{t}\right)}$;

Hydro Turbine: $\frac{\left(1-s T_{w}\right)}{\left(1+0.5 s T_{w}\right)}$;

Power System: $\frac{K_{p}}{\left(1+s T_{p}\right)}$;

Hydro Droop Compensation: $\frac{\left(1+s T_{r}\right)}{\left.1+s\left(R_{t} / R_{p}\right) T_{r}\right)}$

where $R_{i}$ is regulation constant (Hz/per unit), $T_{G}$ is speed governor time constant (s), $T_{T}$ is turbine time constant (s), $T_{p}$ is power system time constant (s), $T_{w}$ is hydro turbine time constant (s), while $T_{r}$ is reset time (s) and $K_{P}$ is transfer function gain of generator.

\section{Parameters of Hydro Thermal System Investigated:}

$\mathrm{P}_{\mathrm{r} 1}=\mathrm{P}_{\mathrm{r} 2}=2000 \mathrm{MW}$;

$\mathrm{K}_{\mathrm{p} 1}=\mathrm{K}_{\mathrm{p} 2}=120$;

$\mathrm{T}_{\mathrm{p} 1=} \mathrm{T}_{\mathrm{p} 2=20}$;

$\mathrm{K}_{\mathrm{r}}=10$;

$\mathrm{R}_{1}=\mathrm{R}_{2}=2.4$;

$\mathrm{T}_{12}=0.545$;

$\mathrm{T}_{\mathrm{w}}=1 ; \mathrm{T}_{\mathrm{t}}=0.3$;

$\mathrm{T}_{\mathrm{g} 1}=0.08 ; \mathrm{T}_{\mathrm{g} 2}=0.02$;

$\mathrm{T}_{\mathrm{r}}=5 ; \mathrm{R}_{\mathrm{t}}=0.38 ; \mathrm{R}_{\mathrm{p}}=0.05$;

$\beta=0.425 ; \mathrm{a}_{12}=1$; 
Parameters of SMES:

Energy $=30 \mathrm{MJ}$

Nominal DC current $($ Id0 $)=4.5 \mathrm{kA}$

Minimum DC current (Idmin) $=4.0 \mathrm{kA}$

Maximum DC current $($ Idmax $)=4.9 \mathrm{kA}$

Convertor Time Constant $(\mathrm{Tdc})=0.03 \mathrm{sec}$

Superconducting Coil Inductance $(\mathrm{L})=2.5 \mathrm{H}$ 